\title{
Пенсионная реформа 2018 года в России и ее влияние на работников градообразующего предприятия в российской Арктике
}

\author{
Скуфьина Т.П., Бажутова Е.А. \\ Институт экономических проблем им. Г.П. Лузина - обособленное подразделение ФГБУН \\ Федерального исследовательского центра «Кольский научный центр Российской академии наук», \\ Россия, 184209, г. Апатиты, Ферсмана 14 \\ E-mail: skufina@gmail.com
}

\begin{abstract}
Аннотация. Исследования, посвященные рассмотрению влияния пенсионных изменений на общественные процессы, являются актуальными во всем мире в силу экономической значимости и социальной заостренности буквально любых изменений в пенсионном законодательстве. Несмотря на очевидную значимость для России, практически отсутствуют оценки влияния пенсионных изменений на социально-экономические процессы в Арктике. Серия авторских исследований частично восполняет этот пробел, подтверждая, что особые арктические условия инициируют повышенные риски устойчивому развитию при реализации пенсионной реформы. В этой статье мы приводим результаты исследования реакции на пенсионные изменения отдельной целевой аудитории персонала градообразующего предприятия, расположенного в российской Арктике. Метод исследования - письменный опрос, выполненный с учетом квот по полу, возрасту, занимаемой должности, условиям труда на градообразующем предприятии. Установлено, что влияние пенсионных изменений на миграционные настроения работников рудообразующего предприятия менее значительно в сравнении с общерегиональной ситуацией. Негативные высказывания работников градообразующего предприятия относительно пенсионной реформы и ее последствий не подтвердили ожидаемого лояльного отношения к пенсионной реформе. Полученные результаты развивают представления о региональных эффектах реализации пенсионной реформы 2018 года.
\end{abstract}

Ключевые слова: Россия, Арктика, пенсионная реформа, региональные эффекты, градообразующее предприятие, работники.

Благодарности: работа включает материалы, полученные в рамках выполнения государственного задания ФГБУН ФИЦ КНЦ РАН № АААА-А18-118051590118-0.

Для цитирования: Скуфьина Т.П., Бажутова Е.А. 2021. Пенсионная реформа 2018 года в России и ее влияние на работников градообразующего предприятия в российской Арктике. Экономика. Информатика, 48 (3): 434-445. DOI 10.52575/2687-0932-2021-48-3-434-445.

\section{Pension reform 2018 in Russia and its impact on workers at a city-forming enterprise in the Russian Arctic}

\author{
Tatiana P. Skufina, Ekaterina A. Bazhutova \\ Luzin Institute for Economic Studies - Subdivision of the Federal Research Centre «Kola Science Centre \\ of the Russian Academy of Sciences» (IES KSC RAS), \\ 14 Fersmana st., Apatity, 184209, Russia \\ E-mail: skufina@gmail.com
}

\begin{abstract}
Studies examining the impact of pension changes on social processes are relevant worldwide due to the economic significance and social sensitivity of literally any change in pension legislation. Despite their obvious importance for Russia, there are virtually no assessments of the impact of pension changes on socioeconomic processes in the Arctic. The author's series of studies partially fills this gap, confirming that the
\end{abstract}


special Arctic conditions initiate greater risks to sustainable development in the implementation of pension reform. In this article, we present the results of a study of reactions to pension changes by a separate target audience - the staff of a city-forming enterprise located in the Russian Arctic. The research method was a written survey based on quotas by gender, age, position and working conditions at the city-forming enterprise. It was found that the impact of pension changes on the migration moods of workers at the town-forming enterprise was less significant compared to the situation in the region. Negative opinions of employees at the backbone enterprises about pension reform and its consequences did not confirm the expected loyal attitude to pension reform. The obtained results develop ideas about the regional effects of the implementation of the pension reform in 2018.

Keywords: Russia, Arctic, pension reform, regional effects, city-forming enterprise, employees.

Acknowledgements: The paper includes materials received as part of the state assignment of KSC RAS No. AAA-A18-118051590118-0.

For citation: Skufina T.P., Bazhutova E.A. 2021. Pension reform 2018 in Russia and its impact on employees of the city-forming enterprise in the Russian Arctic, Economics. Information technologies. 48 (3): 434-445 (in Russian). DOI 10.52575/2687-0932-2021-48-3-434-445.

\section{Введение}

Оценка последствий пенсионной реформы 2018 года для общественных процессов в Российской Федерации является активно разрабатываемой тематикой в силу не только существенности изменений, но и социальной заострённости вопросов, касающихся буквально любых изменений в пенсионном законодательстве, от которых зависит жизнедеятельность практически каждого человека. Активность и основные аспекты разработки этой тематики в России соответствуют мировым исследованиям, которые также определяются экономической и социальной значимостью вопросов, касающихся пенсионной системы, на фоне развития основной демографической проблемы развитых и развивающихся стран - проблемы старения населения [Chistova, 2016; Harper, 2014; Holzmann, 2013].

Особенно ярко социальная острота восприятия населением пенсионных изменений проявилась в Российской Федерации в силу двух основных групп фактов. Первая группа взаимосвязанных факторов - неожиданность введения изменений в пенсионное законодательство Российской Федерации, следовательно, слабая проработка вопроса научным сообществом, неподготовленность населения, нечеткость увязки увеличения численности трудоспособного населения с программами развития экономики и т. д. [Баранов, Скуфьина, 2018; Скуфьина, Баранов, 2019; Торопушина, 2020; Chistova, 2016] . Вторая группа факторов обусловлена тем, что пенсионная реформа обозначила увеличение возраста выхода на пенсию, тогда как в России возраст выхода на пенсию не менялся с 1932 года (составляя с 1932 года по конец 2018 года в нормальном пенсионном возрасте ${ }^{1} 65$ лет для мужчин и 55 лет для женщин). Именно изменение пенсионного возраста - это основная составляющая пенсионных изменений 2018 года, причем, наиболее болезненная для общественного восприятия.

Многочисленные, в том числе и авторские исследования, показывали, что поднятие пенсионного возраста было необходимо в силу высоких темпов перехода населения России в статус населения нетрудоспособного возраста [Кудрин, Гурвич, 2012; Baranov, Skuf'ina, Gushchina, 2020]. Так, рассмотрение динамики численности трудоспособного населения Российской Федерации позволило установить, что максимум численности населения в трудоспособном возрасте был достигнут в 2006 году (90 млн чел.), сменившись спадом, неизбежным с позиций демографии. Согласно расчетам Федеральной службы государственной статистики, при сохранении прежнего (дореформенного) возраста выхода на пенсию к 2036 году численность трудоспособного населения Российской Федерации

\footnotetext{
${ }^{1}$ Сложившийся термин «нормальный пенсионный возраст» (англ. normal retirement age) обозначает возраст, в котором гражданин может получить полную пенсию.
} 
существенно сократится и составит: в низком варианте прогноза 75 млн чел., в среднем варианте прогноза - 79 млн чел., в высоком варианте - 83 млн чел. [Baranov, Skuf'ina, Gushchina, 2020, C. 165-166].

Очевидно, что увеличение возраста выхода на пенсию механически увеличивает численность трудоспособного населения в стране. Наш трехвариантный прогноз, выполненный совместно с д.ф.-м.н. Барановым С.В. для пенсионного возраста, установленного согласно новой схеме выхода на пенсию, указывает на следующий важный макроэкономический факт. Увеличение возраста выхода на пенсию качественно изменило ситуацию, сломав нисходящий тренд показателя численности трудоспособного населения в Российской Федерации на противоположный. Так, наш трехвариантный прогноз показывает, что значение 2006 года численности трудоспособного населения Российской Федерации при высоком варианте прогноза будет достигнуто к 2029 году, при среднем варианте - к 2032 году. При низком варианте, несмотря на тенденцию роста, к 2036 году значение максимума 2006 года достигнуто не будет [Скуфьина, Баранов, 2019].

Исследования показывают, что особенно проблема старения населения актуальна для территорий российской Арктики, в которых отток населения трудоспособного возраста и льготный возраст выхода на пенсию обеспечивают более высокие темпы потери трудоспособного населения. Еще более усиливают эту проблему низкие медико-демографические резервы территории российской Арктики [Торопушина, 2020]. Наши расчеты и прогнозные разработки убедительно показывают, что увеличение пенсионного возраста при прочих равных условиях в перспективе снизит скорость сокращения населения трудоспособного возраста на арктических территориях России [Baranov, Skuf'ina, Gushchina, 2020].

Однако влияние изменений пенсионного возраста на социальную и экономическую жизнедеятельность в любой стране многофакторное, что априори означает многосоставной и неоднозначный характер этого влияния [Bielecki, 2016; Holzmann, 2017; Peng, Mai, 2013; Puur, Leppik, Klesment, 2015]. Ряд исследований показывает, что поднятие пенсионного возраста породило и ряд неблагоприятных фактов и тенденций социального и экономического развития в Российской Федерации. Например, массовые опросы, проведенные нами по репрезентативной выборке в 2019 году на территории Мурманской области (область относится к регионам, расположенным в зоне Арктики), а в 2021 году - во всех регионах российской Арктики, указывают на возможное усиление миграционного оттока населения с этих территорий. Причем значительная часть респондентов увязывала желание уехать с арктических территорий именно с увеличением возраста выхода на пенсию [Baranov, Skuf' ina, Gushchina, 2020]. Усиление миграционных настроений создает риск нивелирования благоприятного влияния увеличения пенсионного возраста на численность населения трудоспособного возраста на территории Арктики. Таким образом, например, составленный нами на основе экономико-математических методов долгосрочный прогноз, указывающий на увеличение численности трудоспособного населения в Мурманской области, может быть существенно скорректирован вероятным усилением миграции. Другой пример, указывающий на неоднозначность оценок характера влияния повышения пенсионного возраста для общества это проявившаяся в ряде регионов проблема недостаточности медико-демографических резервов для поднятия пенсионного возраста [Торопушина, 2020].

Таким образом часть неблагоприятных проявлений пенсионных изменений инициирована региональными особенностями. Действительно, и демографические, и медикодемографические, и социальные, и экономические и даже институциональные процессы существенно отличаются между регионами России, порождая специфику воздействия, в том числе, пенсионных изменений на жизнедеятельность в регионах [Самарина, 2012; Samarina, Samarin, Skufina, 2021; Stryabkova et al., 2019]. Несмотря на явное усиление региональных аспектов при принятии управленческих решений, многочисленные исследования указывают на необходимость еще более глубокого учета региональных особенностей в практике управления [Ускова, 2016; Shabunova, Kozhevnikov, 2020]. В этой связи актуальность настоящего 
исследования с научно-практической точки зрения и его фундаментальная значимость определяются тем, что именно региональный срез в оценках последствий пенсионной реформы 2018 года до сих пор является наименее изученным.

\section{Объекты и методы исследования}

Учитывая разнообразие регионов Российской Федерации, следовательно, ожидаемое разнообразие региональных эффектов влияния пенсионных изменений, определим территориальный объект исследования - арктическую территорию России. Это обусловлено тремя основными причинами. Во-первых, общепризнанно, что особые арктические условия жизнедеятельности, порождающие высокие издержки социальной сферы и ведения бизнеса, определяют усиление рисков от внешних воздействий, включая изменения в пенсионной системе [Экономика современной Арктики.., 2020]. Во-вторых, эти особые условия предопределяют необходимость проведения специфической арктической политики и мер государственного управления, что закономерно отражается и в институциональных условиях, определяющих вектор развития российской и зарубежной Арктики [Kudryashova, Zarubina, Sivobrova, 2019; Leksin, Porfiryev, 2017]. В третьих, перед российской Арктикой поставлены значимые задачи социально-экономического развития, требующие развития человеческого капитала, включая высокое качество трудового потенциала населения, зависящего, в том числе, от влияния действующей пенсионной системы [Экономика современной Арктики.., 2020; Larchenko, Kolesnikov, 2018].

Для оценки влияния пенсионных изменений на социально-экономические процессы и прогнозирование последствий от реализации в аспекте текущих задач и проблем по развитию Арктики нами было проведено исследование общественного мнения и ожиданий населения относительно принятой пенсионной реформы. Исследование масштабное, включило несколько задач и этапов, выполненных в период 2019-2021 годов.

В этой работе мы представляем еще не опубликованную часть результатов, которые посвящены исследованию реакции на пенсионные изменения отдельной целевой аудитории персонала градообразующего предприятия, расположенного в Арктической зоне Российской Федерации (АЗРФ). Выбор данной категории населения для отдельного исследования обоснован тем, что на территории АЗРФ находится около 7 \% моногородов России, при этом, как правило, градообразующими предприятиями в них являются крупные горнопромышленные компании, отличающиеся высокой корпоративной социальной ответственностью (КСО).

Результаты ряда зарубежных и отечественных исследований подтверждают в целом соответствие (по некоторым аспектам - превышение) уровня и разнообразия социальных гарантий крупных предприятий в российской Арктике уровню и разнообразию социальных гарантий крупных предприятий зарубежных стран, ведущих работы на арктических территориях [Skufina et al., 2019; Suopajärvi et al., 2017]. Однако эта особенность лишь частично нивелирует традиционные проблемы моногородов АЗРФ, включая демографические [Социально-экономическое развитие Северо-Арктических территорий России, 2019; Korchak, Serova, 2019].

Внушительные социальные гарантии, предоставляемые крупным бизнесом на территории российской Арктики в рамках своих программ КСО, создают условия социальной защищенности персонала. Наличие более благоприятных условий работы у сотрудников градообразующего предприятия по отношению к среднероссийским и «общеарктическим», предопределили гипотезу настоящего исследования о том, что влияние пенсионных изменений на миграционные настроения работников градообразующего предприятия будет меньше в сравнении с остальными жителями региона, а их отношение к данной реформе будет более лояльным. Таким образом, цель этого исследования - оценка влияния пенсионной реформы на отношение работников градообразующего предприятия к жизнедеятельности в 
Арктике. Постановка такой цели имеет не только значение для науки, но также и существенное практическое значение для регионального развития, а также для учета результатов при разработке обоснованного прогноза корпоративного развития АЗРФ.

Объект исследования - Кировский филиал акционерного общества «Апатит» (КФ АО «Апатит»), расположенный в АЗРФ.

Метод исследования - письменный опрос (анкетирование). Количество опрошенных 70 чел. Опрос выполнен с учетом квот по полу, возрасту, занимаемой должности, условиям труда на градообразующем предприятии.

\section{Результаты и их обсуждение}

На рисунках приведены наиболее значимые результаты проведенного опроса. Обращает внимание, что на ключевой вопрос об отношении работников к проведенной пенсионной реформе более $70 \%$ респондентов дали отрицательную оценку пенсионным изменениям (рис. 1). При этом наиболее категоричными в данных оценках были респонденты от 41 до 50 лет (рис 2), причем преимущественно мужчины, а в части возраста - респонденты от 41 до 50 лет. Однозначно отрицательно данную реформу оценили работники, относящиеся к категории рабочих и сотрудники, трудящиеся в тяжелых и опасных условиях труда. Наиболее рационально и лояльно к пенсионным изменениям отнеслись респонденты, занимающие руководящие должности.

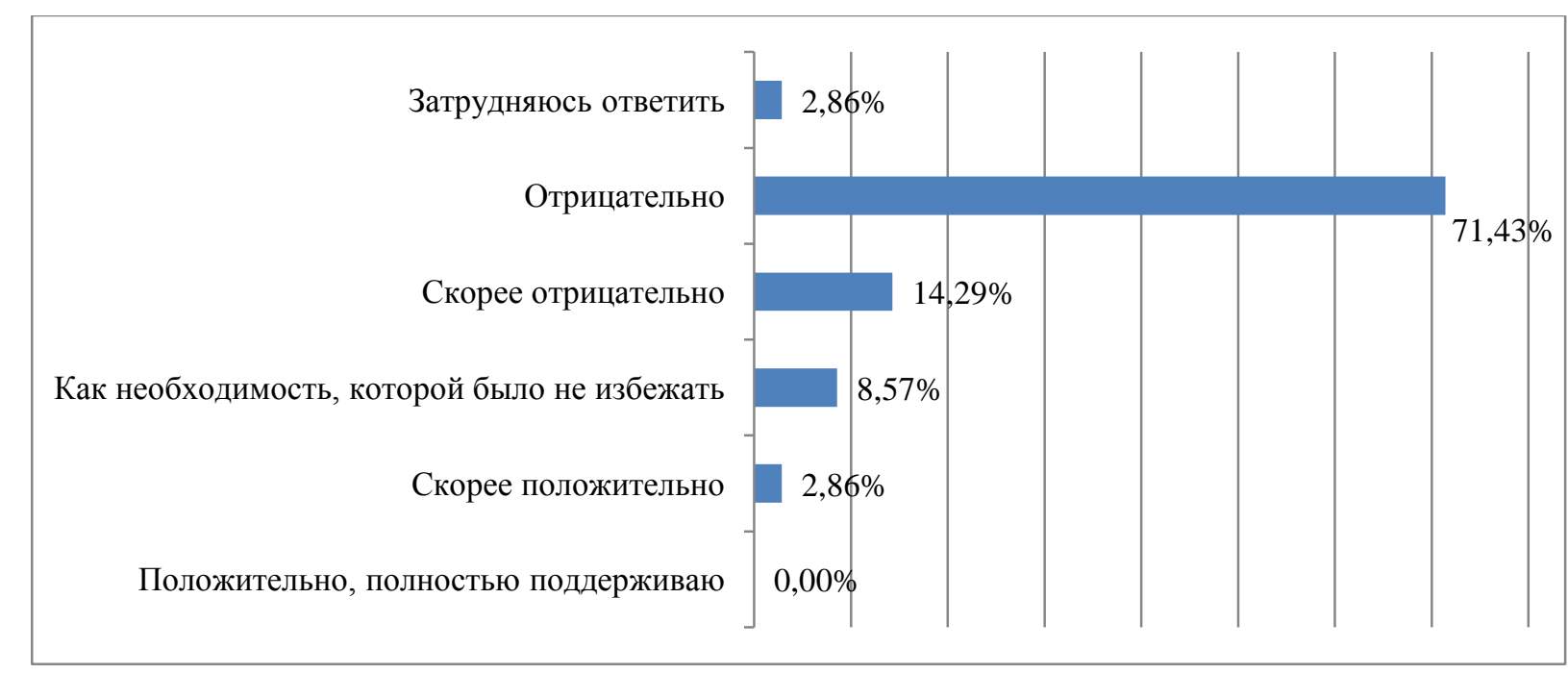

Рис. 1. Ответы респондентов на вопрос «Как Вы оцениваете увеличение пенсионного возраста по пенсионной реформе 2018 года?»

Fig. 1. Answers of respondents to the question "How do you assess the increase in the retirement age under the pension reform of 2018?"

Однозначно отрицательно данную реформу оценили работники, относящиеся к категории рабочих и сотрудники, трудящиеся в тяжелых и опасных условиях труда. Так, отрицательно восприняли пенсионные изменения $100 \%$ работников, попадающих под распространение пенсионных Списков № 1 и № 2, дающих право на льготное пенсионное обеспечение в связи с работой в тяжелых и опасных условиях. Среди остальных работников только $60 \%$ отнеслись отрицательно, $20 \%$ - скорее отрицательно, $12 \%$ - как к необходимости, которой было не избежать. Отметим, не было ни одного ответа «положительно, полностью поддерживаю». 


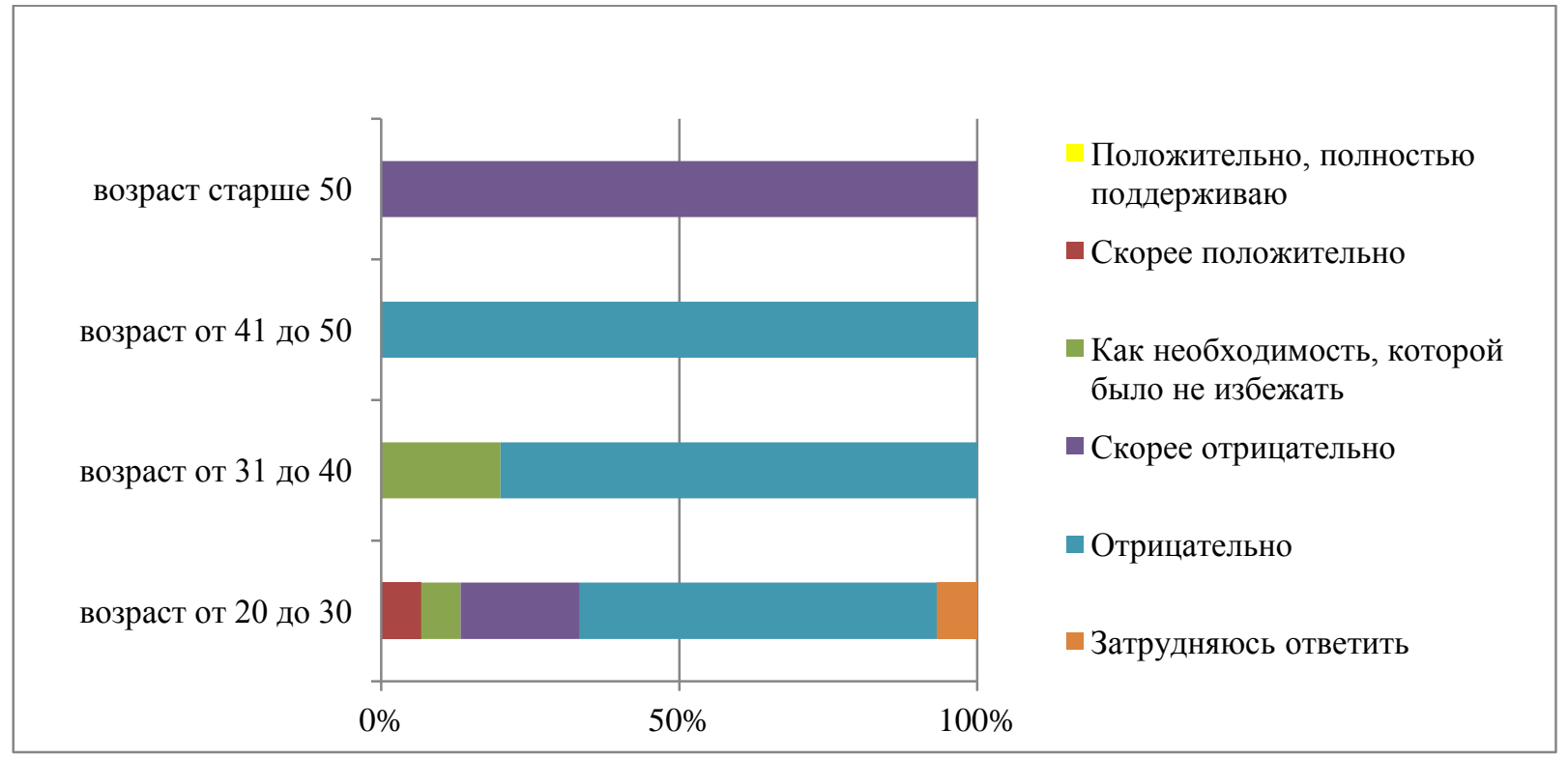

Рис. 2. Отношение к пенсионным изменениям 2018 года респондентов в зависимости от возраста Fig. 2. Respondents' attitudes towards the 2018 pension changes by age

Рассмотрение специфики восприятия пенсионных изменений респондентами в зависимости от категорий персонала указывает на существенные различия ответов респондентов между категориями (табл. 3). Так, 100 \% рабочих высказали свое отрицательное отношение к пенсионным изменениям 2018 года. Несколько более смягченное отношение наблюдалось у ИТР (53\% - отрицательное отношение, $29 \%$ - скорее отрицательное, но при этом 6\% - скорее положительное и еще 6\% воспринимают изменения 2018 года как необходимость, которой было не избежать). Наиболее рационально и лояльно к пенсионным изменениям отнеслись респонденты, занимающие руководящие должности, среди которых нашлось 29 \%, оценивших пенсионные изменения как необходимость которой не избежать (рис. 3).

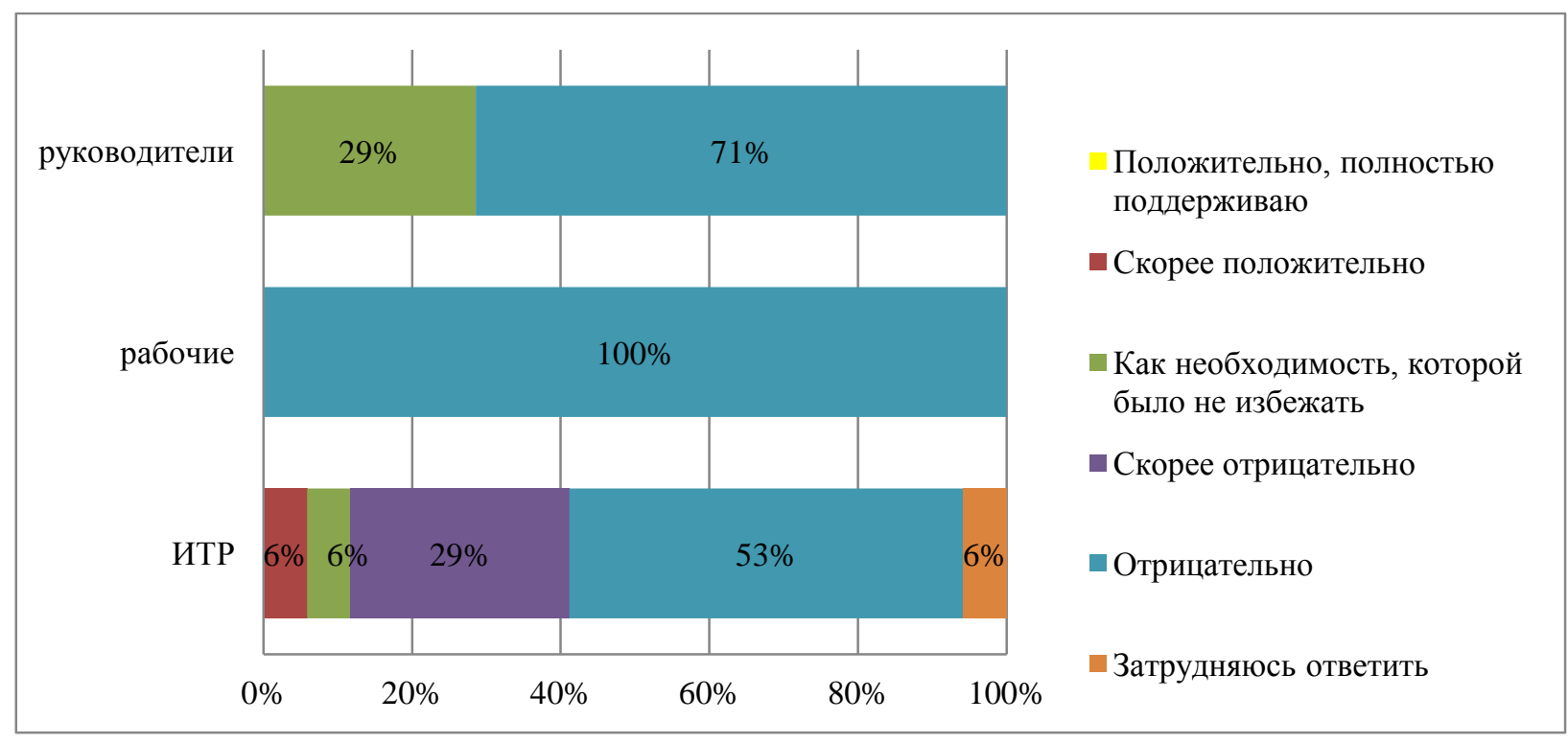

Рис. 3. Отношение к пенсионным изменениям 2018 года респондентов в зависимости от категорий персонала

Fig. 3. Respondents' attitudes towards the 2018 pension changes according to staff categories 
Определенный интерес имеет изучение мнений респондентов относительно положительных и негативных эффектов реализации пенсионных изменений 2018 года. $64 \%$ респондентов отметили больше отрицательных эффектов от реализации пенсионной реформы, чем положительных. В качестве основных отрицательных эффектов от реализации пенсионной реформы были выделены: рост риска «недоживания» до пенсионного возраста (в большей степени респондентами в возрасте старше 50 лет), рост конфликтности в обществе и безработицы населения. Также в качестве отрицательного эффекта были отмечены риски снижения реальных доходов населения и замедления темпов роста пенсий (детализация данных показала, что эти ответы отмечены преимущественно респондентами старше 50 лет) (рис. 4).

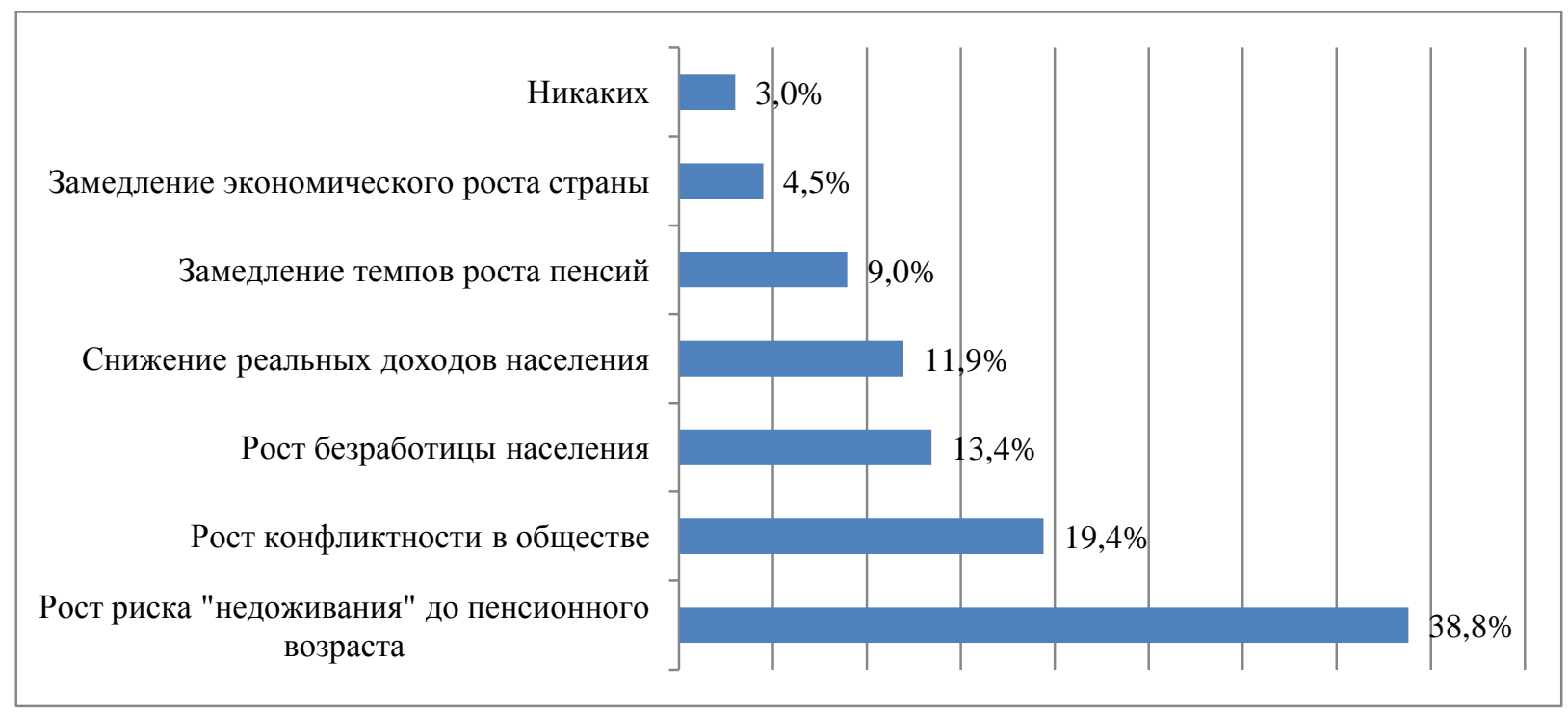

Рис. 4. Ответы респондентов на вопрос «Какие отрицательные стороны пенсионной реформы 2018 года Вы можете выделить?

Fig. 4. Answers of respondents to the question "What negative aspects of the 2018 pension reform can you highlight?

По мнению респондентов, основные положительные эффекты от реализации пенсионной реформы 2018 года следующие: сохранение льгот досрочного выхода на пенсию для отдельных категорий граждан (этот эффект выделен респондентами, занимающими должность рабочих и ИТР, преимущественно относящимися к категории возраста старше 50 лет); рост численности трудоспособного населения в экономике (в большей части обозначен респондентамируководителями) (рис. 5).

Однако, несмотря на преимущественно отрицательную оценку реформы и её последствий, опросы показали, что реализация пенсионных изменений практически не инициировала желание сменить занимаемую должность и условия труда у работников ИТР и руководителей, а у работников с условиями труда, попадающими под распространение пенсионных Списков № 1 и № 2, только 10 \% задумалось об увольнении.

В связи со значительностью проблемы миграционных потерь арктических территорий, вопрос, касающийся миграционных настроений работников градообразующего предприятия, являлся наиболее актуальным. Опрос показал, что чуть более $14 \%$ респондентов связали свое желание уехать с территории Арктики именно с пенсионной реформой, еще почти 8,6\% указали на нее как на возможную причину желаемого отъезда (рис. 6). Отметим, что эти цифры являются достаточно высокими, свидетельствуя о негативном влиянии пенсионных изменений на миграционные настроения работников градообразующего предприятия. Однако сравнение с результатами массовых опросов в Мурманской области, проведенных нами в 2019 году, указывает, что миграционные настроения, вызванные в первую очередь увеличением пенсионного возраста, менее сильны у работников градообразующего предприятия, чем в целом по Мурманской области. Так, согласно нашим предшествующим опросам, по 
Мурманской области в целом, при ответе на вопрос «Изменились ли Ваши планы в отношении дальнейшего проживания в Мурманской области в связи с увеличением пенсионного возраста?» 7,5 \% опрошенных уже точно не собираются больше проживать в Мурманской области и подыскали место работы в другом регионе, а 25,6 \% скорее изменили планы и думают о переезде в более комфортные климатические условия [Baranov, Skuf'ina, Gushchina, 2020]. Причем углубление полученных данных опросов по Мурманской области в целом указало на то, что арктический регион собираются покидать наиболее экономически активное население - молодежь и жители 30-49 лет.

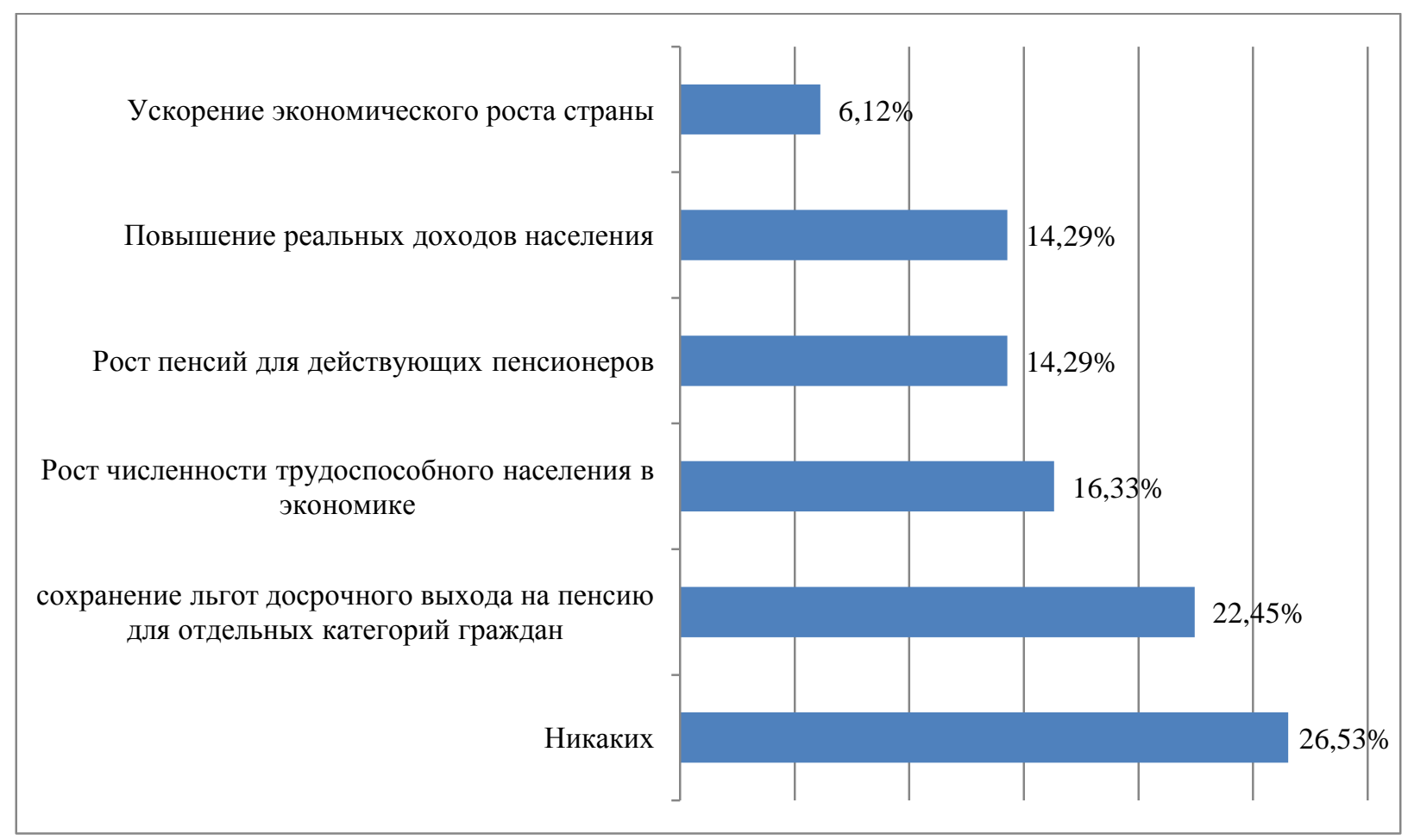

Рис. 5. Ответы респондентов на вопрос «Какие положительные стороны пенсионной реформы 2018 года Вы можете выделить?»

Fig. 5. Respondents' answers to the question "What positive aspects of the 2018 pension reform can you highlight?"

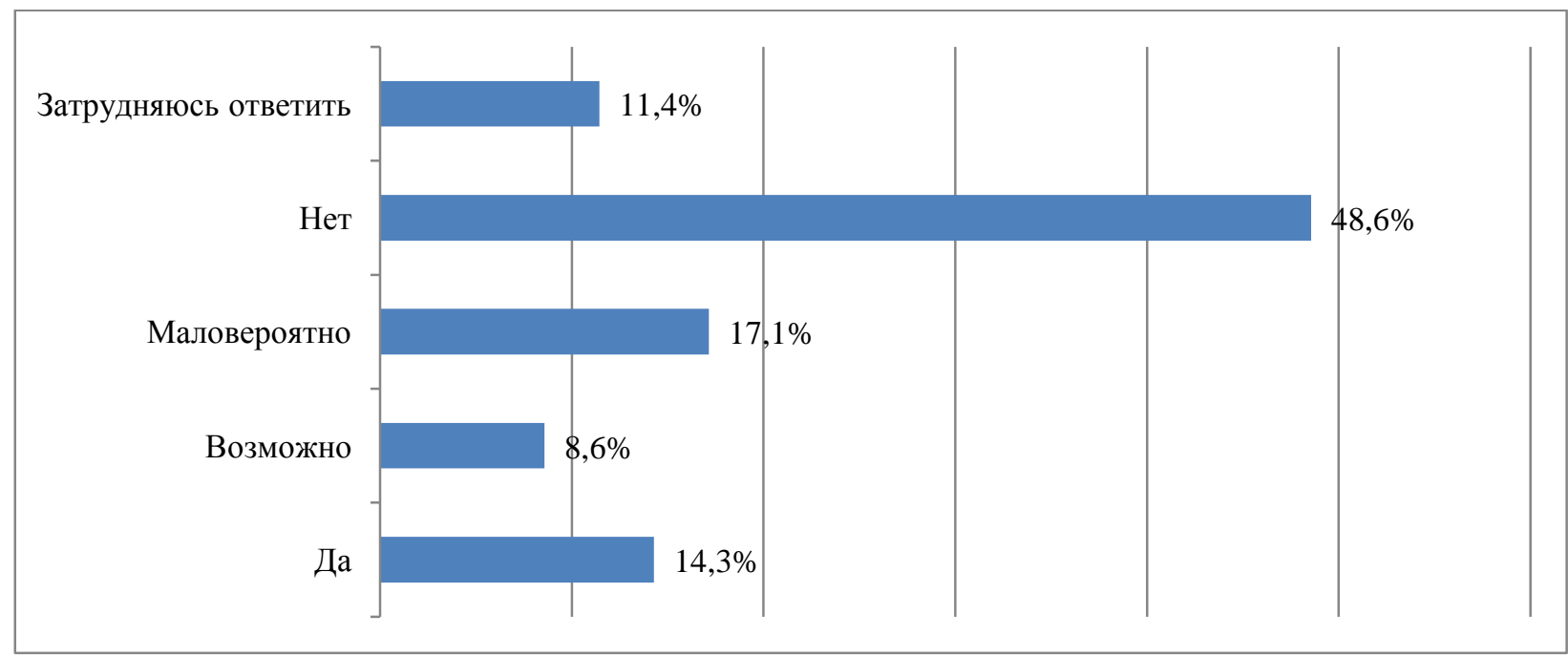

Рис. 6. Ответы респондентов на вопрос «Оказала ли пенсионная реформа 2018 года влияние на Ваше желание уехать с Севера?»

Fig. 6. Answers of respondents to the question "Has the pension reform of 2018 influenced your desire to leave the North? 
Выявленное отличие ситуации на градообразующем предприятии от ситуации в целом по Мурманской области подтверждает то, что работники градообразующего предприятия держатся за высокооплачиваемую, стабильную работу со значительными социальными льготами, обеспеченную КФ АО «Апатит».

\section{Заключение}

Подводя итоги, отметим, что гипотеза нашего исследования подтверждена частично. Так, подтверждена гипотеза исследования в той части, что фактическое влияние пенсионных изменений на миграционные настроения работников градообразующего предприятия, расположенного в АЗРФ, будет менее значительным, чем для населения региона в целом. Действительно, миграционные настроения работников градообразующего предприятия арктического региона, увязанные в сознании респондентов с пенсионными изменениями 2018 года, менее сильны, чем у остального населения этого региона. Это подтверждает стабилизирующую роль градообразующих предприятий для социально-экономической жизнедеятельности АЗРФ. Также это подтверждает, что именно экономический фактор и социальная стабильность по-прежнему являются основными факторами влияния на решение работников относительно проживания в АЗРФ.

Вместе с тем опросы не подтвердили гипотезу в той части, что отношение к пенсионным изменениям более лояльно у работников градообразующего предприятия в сравнении с общерегиональной ситуацией. Категоричность негативных высказываний относительно отношения к пенсионной реформе и анализ мнений респондентов относительно ее последствий указывают на недостаточность разъяснительной работы государства при подготовке изменений в пенсионное законодательство.

В целом следует заключить, что последствия пенсионной реформы несут сложные эффекты для региональных экономик, в частности, для экономики АЗРФ. Риски усиления миграционных настроений населения на арктических территориях России говорят о необходимости продолжения исследований влияния пенсионных изменений на умонастроения в обществе. Особенно усиливает необходимость таких исследований влияние кризиса, вызванного COVID-19, который обостряет системные проблемы Арктики, в частности проблему усиленного миграционного оттока населения.

\section{Список литературы}

1. Баранов С.В., Скуфьина Т.П. 2018. Влияние повышения пенсионного возраста на производство валового внутреннего продукта в России. Инновации, 9: 38-44.

2. Кудрин А., Гурвич Е. 2012. Старение населения и угроза бюджетного кризиса. Вопросы экономики, 3: 52-79.

3. Самарина В.П. 2012. Показатели реакции регионов Центрального федерального округа на изменение внешних условий. Региональная экономика: теория и практика, 14.: 2-10.

4. Скуфьина Т.П., Баранов С.В. 2019. Пенсионная реформа в России: оценка чувствительности производства ВВП к сдвигу численности трудоспособного населения. Экономика и управление, 9: 80-86.

5. Социально-экономическое развитие Северо-Арктических территорий России: коллективная монография. Апатиты: КНЦ РАН, 2019. DOI: 10.25702/KSC.978.5.91137.408.2

6. Торопушина Е.Е. 2020. Влияние повышения пенсионного возраста на изменение медикодемографических резервов регионов Арктической зоны Российской Федерации. Экономика труда, 7(7): 617-630.

7. Ускова Т.В. 2016. Проблемы эффективности государственного управления. Экономика Северо-Запада: проблемы и перспективы развития, 1 (50): 11-23.

8. Экономика современной Арктики: в основе успешности эффективное взаимодействие и управление интегральными рисками. Апатиты: КНЦ РАН, 2020. DOI: 10.37614/978.5.91137.416.7

9. Baranov S.V., Skuf'ina T.P., Gushchina I.A. 2020. The Impact of the Retirement Age Increase on the Economy and Attitudes of the Population of the Murmansk Oblast. Economic and Social Changes: Facts, Trends, Forecast, 13 (1): 160-173. 
10. Bielecki M. et al. 2016. Decreasing fertility vs increasing longevity: Raising the retirement age in the context of ageing processes. Economic Modelling, 52: 125-143.

11. Chistova E.V. 2016. Possibilities for increasing the retirement age in Russia in response to population ageing. Montenegrin Journal of Economics, 12 (3): 127-138.

12. Harper S. 2014. Economic and Social Implications of Aging Societies. Science, 6209: 587-591.

13. Holzmann R. 2017. An optimistic perspective on population ageing and old-age financial protection. Malaysian Journal of Economic Studies, 50 (2): ,107-137.

14. Holzmann R. 2013. Global pension systems and their reform: worldwide drivers, trends and challenges. International Social Security Review, 66 (2): 1-29.

15. Korchak E., Serova N. 2019. High-quality reproduction of labor potential of Arctic territories: migration factor. The European Proceedings of Social \& Behavioural Sciences EpSBS. V. LXXVI: 1736-1742.

16. Kudryashova E.V., Zarubina L.A., Sivobrova I.A. 2019. Cross-Border Investment Cooperation in the Arctic Region: Challenges and Opportunities. Economic and Social Changes: Facts, Trends, Forecast, 1:39-52.

17. Larchenko L.V., Kolesnikov R.A. 2018. Regions of the Russian Arctic zone: state and problems at the beginning of the new development stage. International journal of engineering and technology, 7(3): 369-375.

18. Leksin V.N., Porfiryev B.N. 2017. Specificities of Spatial System Transformation and Strategies of the Russian Arctic Redevelopment under the Conditions of Climate Changes. Economy of region, 13 (3): 641-657.

19. Peng X., Mai Y. Population Ageing, Retirement Age Extension and Economic Growth in China: A Dynamic General Equilibrium Analysis. Centre of Policy Studies and the Impact Project, 2013.

20. Puur A., Leppik L., Klesment M. 2015. Changes in pension take-up and retirement in the context of increasing the pension age: the case of Estonia in the 2000s. Post-Communist Economies, 27 (4): 497-516.

21. Samarina V.P., Samarin A.V., Skufina T.P. 2021. Problems of pensioners and other residents of the Russian arctic monotowns. CDSES 2020, 105: 765-774.

22. Shabunova A.A., Kozhevnikov S.A.2020. Public administration efficiency in studies of the Vologda Research Center of RAS. Economic and Social Changes: Facts, Trends, Forecast, 13 (5): 9-21.

23. Skufina, T., Bazhutova, E., Samarina, V., \& Serova, N. 2019. Corporate Social Responsibility as a Reserve for the Growth of Entrepreneurial Activity in the Russian Arctic. Humanities \& Social Sciences Reviews, 7(6): 1024-1031.

24. Stryabkova E.A., Kogteva A.N., Kulik A.M. \& Gerasimova N.A. 2019. The development of the digital economy in the Belgorod region. Humanities \& Social Sciences Reviews, 7(5): 782-788.

25. Suopajärvi L., Ejdemo Th., Klyuchnikova E., Korchak E., Nygaard V., Poelzer G.A. 2017. Social impacts of the "glocal" mining business: case studies from Northern Europe. Mineral Economics, 30 (1): 31-39.

\section{References}

1. Baranov S.V., Skuf'ina T.P. 2018. Vliyanie povysheniya pensionnogo vozrasta na proizvodstvo valovogo vnutrennego produkta $v$ Rossii [The impact of raising the retirement age on the production of gross domestic product in Russia]. Innovatsii, 9: 38-44 (In Russian).

2. Kudrin A., Gurvich E. Starenie naseleniya i ugroza byudzhetnogo krizisa [The aging of the population and the threat of a budget crisis]. Voprosy Ekonomiki, 3: 52-79 (In Russian).

3. Samarina V.P. 2012. Pokazateli reakcii regionov Central'nogo federal'nogo okruga na izmenenie vneshnih uslovij [Indicators of the reaction of the regions of the Central Federal District to changes in external conditions]. Regional'naya ekonomika: teoriya i praktika, 14: 2-10 (In Russian).

4. Skufina T.P., Baranov S.V. 2019. Pensionnaya reforma v Rossii: ocenka chuvstvitel'nosti proizvodstva VVP k sdvigu chislennosti trudosposobnogo naseleniya [Pension reform in Russia: assessment of the sensitivity of GDP production to the shift in the number of able-bodied populations]. Ekonomika $\mathrm{i}$ upravlenie, 9: 80-86 (In Russian).

5. Sotsial'no-ekonomicheskoe razvitie Severo-Arkticheskikh territoriy Rossii [Socio-economic development of the North-Arctic territories of Russia]. Apatity, KSC RAS Publ., 2019 (In Russian) DOI: 10.25702/KSC.978.5.91137.408.2

6. Toropushina E.E. 2020. Vliyanie povysheniya pensionnogo vozrasta na izmenenie medikodemograficheskikh rezervov regionov Arkticheskoy zony Rossiyskoy Federatsii [The impact of raising the retirement age on changes in the medical and demographic reserves of the regions of the Arctic zone of the Russian Federation]. Ekonomika truda, 7 (7): 617-630 (In Russian). 
7. Uskova T.V. 2016. Problemy effektivnosti gosudarstvennogo upravleniya [Problems of public administration efficiency]. Ekonomika Severo-Zapada: problemy i perspektivy razvitiya, 1 (50): 11-23 (In Russian).

8. Ekonomika sovremennoy Arktiki: v osnove uspeshnosti effektivnoe vzaimodeystvie i upravlenie integral'nymi riskami [The economy of the modern Arctic: effective interaction and integrated risk management are at the heart of success]. Apatity, KSC RAS Publ., 2020 (In Russian) DOI: 10.37614/978.5.91137.416.7

9. Baranov S.V., Skuf'ina T.P., Gushchina I.A. 2020. The Impact of the Retirement Age Increase on the Economy and Attitudes of the Population of the Murmansk Oblast. Economic and Social Changes: Facts, Trends, Forecast, 13 (1): 160-173.

10. Bielecki M. et al. 2016. Decreasing fertility vs increasing longevity: Raising the retirement age in the context of ageing processes. Economic Modelling, 52: 125-143.

11. Chistova E.V. 2016. Possibilities for increasing the retirement age in Russia in response to population ageing. Montenegrin Journal of Economics, 12 (3): 127-138.

12. Harper S. 2014. Economic and Social Implications of Aging Societies. Science,6209: 587-591.

13. Holzmann R. 2017. An optimistic perspective on population ageing and old-age financial protection. Malaysian Journal of Economic Studies, 50 (2): ,107-137.

14. Holzmann R. 2013. Global pension systems and their reform: worldwide drivers, trends and challenges. International Social Security Review, 66 (2): 1-29.

15. Korchak E., Serova N. 2019. High-quality reproduction of labor potential of Arctic territories: migration factor. The European Proceedings of Social \& Behavioural Sciences EpSBS. V. LXXVI: 17361742.

16. Kudryashova E.V., Zarubina L.A., Sivobrova I.A. 2019. Cross-Border Investment Cooperation in the Arctic Region: Challenges and Opportunities. Economic and Social Changes: Facts, Trends, Forecast, 1: 39-52.

17. Larchenko L.V., Kolesnikov R.A. 2018. Regions of the Russian Arctic zone: state and problems at the beginning of the new development stage. International journal of engineering and technology, 7(3): 369375.

18. Leksin V.N., Porfiryev B.N. 2017. Specificities of Spatial System Transformation and Strategies of the Russian Arctic Redevelopment under the Conditions of Climate Changes. Economy of region, 13 (3): 641-657.

19. Peng X., Mai Y. Population Ageing, Retirement Age Extension and Economic Growth in China: A Dynamic General Equilibrium Analysis. Centre of Policy Studies and the Impact Project, 2013.

20. Puur A., Leppik L., Klesment M. 2015. Changes in pension take-up and retirement in the context of increasing the pension age: the case of Estonia in the 2000s. Post-Communist Economies, 27 (4): 497-516.

21. Samarina V.P., Samarin A.V., Skufina T.P. 2021. Problems of pensioners and other residents of the Russian arctic monotowns. CDSES 2020, 105: 765-774.

22. Shabunova A.A., Kozhevnikov S.A.2020. Public administration efficiency in studies of the Vologda Research Center of RAS. Economic and Social Changes: Facts, Trends, Forecast, 13 (5): 9-21.

23. Skufina, T., Bazhutova, E., Samarina, V., \& Serova, N. 2019. Corporate Social Responsibility as a Reserve for the Growth of Entrepreneurial Activity in the Russian Arctic. Humanities \& Social Sciences Reviews, 7(6): 1024-1031.

24. Stryabkova E.A., Kogteva A.N., Kulik A.M. \& Gerasimova N.A. 2019. The development of the digital economy in the Belgorod region. Humanities \& Social Sciences Reviews, 7(5): 782-788.

25. Suopajärvi L., Ejdemo Th., Klyuchnikova E., Korchak E., Nygaard V., Poelzer G.A. 2017. Social impacts of the "glocal" mining business: case studies from Northern Europe. Mineral Economics, 30 (1): 31-39.

Конфликт интересов: о потенциальном конфликте интересов не сообщалось.

Conflict of interest: no potential conflict of interest related to this article was reported. 


\section{ИНФОРМАЦИЯ ОБ АВТОРАХ}

Скуфьина Татьяна Петровна, доктор экономических наук, профессор, главный научный сотрудник Института экономических проблем им. Г.П. Лузина - обособленного подразделения ФГБУН Федерального исследовательского центра «Кольский научный центр Российской академии наук», Апатиты, Россия

Бажутова Екатерина Андреевна, младший научный сотрудник Института экономических проблем им. Г.П. Лузина - обособленного подразделения ФГБУН Федерального исследовательского центра «Кольский научный центр Российской академии наук», Апатиты, Россия

\section{INFORMATION ABOUT THE AUTHORS}

Tatiana P. Skufina, Doctor of Economics, Professor, Chief Researcher of the Luzin Institute for Economic Studies - Subdivision of the Federal Research Centre «Kola Science Centre of the Russian Academy of Sciences» (IES KSC RAS), Apatity, Russia

Ekaterina A. Bazhutova, Junior Researcher of the Luzin Institute for Economic Studies - Subdivision of the Federal Research Centre «Kola Science Centre of the Russian Academy of Sciences» (IES KSC RAS), Apatity, Russia 